\title{
Preparo e caracterização de tinturas das folhas de chá verde [Camellia sinensis (L.) O. Kuntze] Theaceae
}

\author{
SANTOS, C.B.; BERNARDINO, G.Z.; SOARES, F.J.; ESPINDOLA, J.D.; ARRUDA, P.M.R.; PAULA, J.R.; \\ CONCEIÇÃO, E.C.; BARA, M.T.F. \\ Universidade Federal de Goiás (UFG). Faculdade de Farmácia. Av. Universitária com 1a Avenida s/n, Setor \\ Universitário. Caixa Postal 131, CEP: 74.605-220, Goiânia-Brasil *mbara@farmacia.ufg.br, mtbara@gmail.com. \\ *Autor para correspondência: Faculdade de Farmácia, Universidade Federal de Goiás. Praça Universitária s/ \\ $n^{\circ}$. Setor Universitário. Goiânia-GO, Brasil. Cep: 74.605-220. Tel: (62)3209-6182. e-mail: mbara@farmacia.ufg. \\ br, mtbara@gmail.com
}

\begin{abstract}
RESUMO: Tinturas preparadas com as folhas de Camellia sinensis (chá verde), foram caracterizadas visando a obtenção de extratos enriquecidos em polifenóis. As tinturas foram obtidas por meio de maceração estática da droga pulverizada, com diferentes misturas de 60, 70, 80 e 94,5\% de etanol em água. Em seguida foram filtradas e, após 8 dias de extração, realizaram-se as analises: organoléptica, $\mathrm{pH}$, densidade, determinação do resíduo seco, perfil cromatográfico por camada delgada, e teor de polifenóis. Os resultados demonstraram que o solvente (mistura hidroalcoólica a 60 ou $70 \%$ ) extraiu a maior quantidade de constituintes químicos do chá verde; também foi o mais seletivo ao extrair, especificamente os polifenóis. Estes dados sugerem que a utilização de álcool etílico a 60 ou $70 \%$ conduz à obtenção de tinturas mais ricas em polifenóis, a partir das folhas do chá verde (C. sinensis).
\end{abstract}

Palavras-chave: planta medicinal, green tea, polifenóis, extratos vegetais, controle de qualidade.

ABSTRACT: Preparation and characterization of Theaceae green tea [Camellia sinensis (L.) O. Kuntze] leaf tinctures. In this work, we prepared and characterized Camellia sinensis leaf tinctures aiming to obtain a polyphenol-enriched extract. The tinctures were prepared through the static maceration process of the powdered drug, at different mixtures $60,70,80$ and $94.5 \%$ of ethanol in water. The tinctures were filtered, and after 8 days of extraction, submitted to organoleptic analysis, determination of $\mathrm{pH}$, density analysis, dry residue analysis, thin layer chromatographic profile and polyphenol percentage analysis. The results showed that the 60 or $70 \%$ alcohol-water mixture has the best extraction of the constituents of green tea and it was more selective to extract, specifically, the polyphenols of the plant. These data suggest the use of 60 or $70 \%$ ethanol to carry out polyphenol-enriched tinctures from green tea leaves (C. sinensis).

Keywords: medicinal plant, green tea, polyphenols, vegetable extracts, quality control.

\section{INTRODUÇÃO}

A fitoterapia como prática complementar é um fenômeno social no mundo atual, caracterizado pelas inter-relações biológicas, sociais, culturais e econômicas (Abifisa, 2007).

Camelia sinensis (L.) O. Kuntze é arbusto da família Theaceae conhecida popularmente por chá verde, chá-da-Índia, banchá ou "green tea". As folhas possuem compostos polifenólicos (Liang et al., 2001). As catequinas correspondem a, aproximadamente, $26,7 \%$ dos compostos presentes no chá verde, e, dentre estas, $11 \%$ são galato-3-epigalocatequina, 10\% epigalocatequina, $2 \%$ galato-3-epicatequina, 2,5\% epicatequina, e $15 \%$ polifenóis não identificados (Schimtz et al., 2005). Os principais compostos químicos terapêuticos do material vegetal $C$. sinensis, são potentes antioxidantes de radicais livres, quelantes de metais e inibidores da lipoperoxidação (Fiorini et al., 2005, Kalra et al., 2005), anti-inflamatórios (Nag-Chaudhuri et al., 2005); antimicrobianos (Yam et al., 1997; Turchetti et al., 2005), inibidores da enzima conversora de angiotensina (Barbosa-Filho et al., 2006), auxiliam na prevenção da osteoporose (Das et al., 2004) e podem contribuir na prevenção de câncer (Halder et al., 2005; Senger, Schwanke e Gottlieb, 2010). As catequinas, em particular,

Recebido para publicação em 25/09/2010 
desempenham papel importante no controle do tecido adiposo, principalmente pela regulação que a galato-3-epigalocatequina exerce sobre algumas enzimas relacionadas ao anabolismo e catabolismo lipídico (Senger, Schwanke e Gottlieb, 2010). O chá verde também é usado na indústria de bebidas, sendo, portanto, necessária a caracterização farmacognóstica (Duarte \& Menarin, 2006).

Embora seja uma matéria-prima muito utilizada atualmente, a Farmacopeia Brasileira (2010) não contêm monografia sobre esta planta e, na Farmacopeia Americana (USP 36, 2013), há a monografia do extrato descafeinado de chá verde, com quantificação de polifenóis calculados como galato de (-)-epigalocatequina por cromatografia líquida de alta eficiência.

Alguns trabalhos citados na literatura têm investigado as condições de extração dos princípios ativos presentes em algumas plantas medicinais, tais como: o chá-de-bugre (Saito \& Oliveira, 1986); o hipérico, a castanha-da-índia, o cardo mariano, o açafrão, e o timo (Benthin et al., 1999); o ginseng americano (Fang et al., 2000); o barbatimão (Ardisson et al., 2002); o confrei (Toledo et al., 2003); o alcaçuz (Ong \& Len, 2003); a pariparoba (Noriega et al., 2005); a arnica (Maciel et al., 2006); e a copaíba (Costa-Machado et al., 2013). As condições e a cinética de extração variam conforme o material vegetal e o marcador farmacológico a ser extraído (Ong, 2004; Liao et al., 2008; Pompeu et al., 2009). Existe investigação sobre o chá verde com foco na interação da cafeina, polifenóis, e cálcio, em extração sob infusão (Couzinet-Mossion et al., 2010).

Mediante o exposto, deve-se destacar a importância de se preparar corretamente os extratos vegetais a serem incorporados em formulações farmacêuticas visando à eficiência do fitoterápico. O objetivo deste trabalho foi investigar formas de obtenção de tintura de chá verde ( $C$. sinensis) com fins de otimizar a extração dos marcadores farmacológicos polifenólicos.

\section{MATERIAL E MÉTODO}

\section{Material botânico}

Folhas de Camellia sinensis na forma de pó foram adquiridas da distribuidora Santos Flora Comércio de Ervas ${ }^{\oplus}$, lote ${ }^{\circ}$ BANC 05/02 - Brasil, com data da fabricação em 10/2005 e validade até 10/2008.

\section{Obtenção das tinturas}

As tinturas de chá verde foram preparadas na proporção de $20 \%(\mathrm{p} / \mathrm{v})$, pelo método de maceração, realizada à temperatura de $25^{\circ} \mathrm{C}$, utilizando soluções hidroalcoólicas como veículo extrator a $60,70,80$ ou $94,5 \%$; realizando 3 agitações ao dia, durante 8 dias. Após este período foram realizadas as filtrações em papel de filtro e o volume inicial das tinturas foi completado com o respectivo líquido extrator.

\section{Caracterização organoléptica e fisico- química das tinturas}

Foram observados aspectos relacionados à cor e odor. A densidade foi determinada pelo método do picnômetro, à temperatura de $29^{\circ} \mathrm{C}$.

$\mathrm{Na}$ medição do $\mathrm{pH}$ foi utilizado $\mathrm{pH}$ metro (Tecnal). O resíduo seco foi determinado a partir de $10 \mathrm{~mL}$ de cada tintura, seguido de evaporação do solvente a $40^{\circ} \mathrm{C}$ em capsulas de porcelana e dessecação em estufa a $110^{\circ} \mathrm{C}$ por 60 minutos.

Na quantificação de polifenóis presentes no pó da planta e nas tinturas de chá verde empregouse a metodologia de Hargerman \& Butler para o doseamento de fenóis totais, descrito por Waterman \& Mole (1994) e Prado et al. (2005). Pesou-se 1 grama da droga pulverizada em balão de fundo redondo de $250 \mathrm{~mL}$ e foram adicionados $150 \mathrm{~mL}$ de água destilada. Esta mistura foi aquecida em banhomaria a $80^{\circ} \mathrm{C}$ por 30 minutos e resfriada em água corrente, completando o volume com água destilada até $250 \mathrm{~mL}$. Filtrou-se a mistura em papel de filtro descartando os primeiros $50 \mathrm{~mL}$ do filtrado. Foram transferidos para tubo de ensaio, $2 \mathrm{~mL}$ de solução de lauril sulfato de sódio (LSS) 1\%/trietanolamina 5\%, 1 $\mathrm{mL}$ de solução cromogênica de $\mathrm{FeCl}_{3} 0,16 \%$ e $1 \mathrm{~mL}$ da amostra. Após repouso de 15 minutos, foi feita a leitura da absorbância em $510 \mathrm{~nm}$. Em outro tubo de ensaio foi feito o controle (branco), contendo $2 \mathrm{~mL}$ de solução de LSS 1\%/trietanolamina $5 \%$ e $1 \mathrm{~mL}$ de solução de $\mathrm{FeCl}_{3} 0,16 \%$ e $1 \mathrm{~mL}$ de água destilada. Em seguida, foi feita a determinação de polifenóis nas tinturas obtidas ajustando-se o volume a ser utilizado na análise $(0,1 \mathrm{~mL}$ de cada tintura). Como substância de referência utilizou-se ácido tânico na concentração de $1 \mathrm{mg} \cdot \mathrm{mL}^{-1}$. Foram retiradas alíquotas de 25, 50, 100, 150 e $200 \mu \mathrm{L}$. Completouse o volume para $4 \mathrm{~mL}$. O cálculo da concentração de polifenóis das tinturas foi feito após a regressão linear dos dados obtidos com a curva de calibração. Obteve-se a equação da reta e, a partir desta, foi calculada a porcentagem (\%) de polifenóis em cada tintura pela equação:

\section{$\times 10^{2} / \mathrm{m}$}

$$
\% \text { polifenol }(\mathrm{m} / \mathrm{v})=\text { concentração }\left(\mathrm{mg} \cdot \mathrm{mL}^{-1}\right)
$$

O procedimento foi realizado em triplicata. $\mathrm{Na}$ determinação do perfil cromatográfico por cromatografia em camada delgada (CCD), foi pesado $1 \mathrm{~g}$ da droga moída, acrescentado $5 \mathrm{~mL}$ 
de metanol e colocado sob refluxo por $10 \mathrm{~min}$ em banho-maria. Esta mistura foi filtrada e concentrada até cerca de $0,5 \mathrm{~mL}$ em banho-maria. Foi utilizada cromatoplaca de sílica-gel $\mathrm{GF}_{254}$, com espessura de $250 \mu \mathrm{m}$, como fase estacionária. A fase móvel foi uma mistura de acetato de etila:ácido fórmico:ácido acético glacial:água $(67,57: 7,43: 7,43: 17,57)$. Foram aplicados $20 \mu \mathrm{L}$ das tinturas obtidas, individualmente, em cromatoplacas de $10 \mathrm{~cm}$ de comprimento e, após eluição, as mesmas foram expostas a nebulização de NP (solução de difenilborato de aminoetanol $\mathrm{R}$ a $1 \% \mathrm{~m} / \mathrm{v}$ metanol R) e observadas em comprimentos de onda de 254 e $365 \mathrm{~nm}$ (Santana et al., 2007). Mediu-se o Rf das bandas, que consiste na razão entre a distância percorrida pela amostra e a distância percorrida pela fase móvel.

\section{RESULTADO E DISCUSSÃO}

\section{Características organolépticas e físico- químicas das tinturas obtidas}

Os caracteres organolépticos das tinturas foram muito semelhantes, apresentando coloração verde escura e odor suave. A tintura de graduação alcoólica $94,5 \%$ apresentou coloração mais escura, possivelmente pela maior extração de clorofila.

Das quatro tinturas obtidas foi verificado que, dentre as características físico-químicas, os valores de densidade e resíduo seco da tintura preparada com solução hidroalcoólica a $60 \%$ foram maiores que as demais. Valores maiores de resíduo seco indicam que este solvente foi capaz de extrair maior quantidade de substâncias da planta, enquanto que as diferenças dos valores encontrados para a densidade pode ser reflexo das diferentes concentrações de água nas tinturas obtidas. Os valores de $\mathrm{pH}$ não sofreram muita alteração (Tabela 1). O valor do pH do álcool etílico puro foi de 6,12 e o valor de $\mathrm{pH} 5,7$ na tintura a $60 \%$ pode ser explicada pela extração de polifenóis, que apresentam caráter ácido.

Dentre as tinturas obtidas foi verificado que em relação ao teor de polifenóis também ocorreu variação, sendo as tinturas a 60 e $70 \%$ as que apresentaram maiores teores de polifenóis, portanto, mais enriquecidas em relação aos princípios ativos fenólicos. Pode-se observar que à medida que aumentou a concentração de etanol, diminuiu a concentração de polifenóis (Tabela 1).

Não foi aplicado teste estatístico entre as diferentes tinturas, uma vez que foi realizada somente a análise qualitativa dos dados após a quantificação dos mesmos. Nosso objetivo foi somente mostrar que, de acordo com o líquido extrator usado no preparo da tintura, as características físico-quimicas foram diferentes e assim chamar a atenção de que, para cada planta medicinal, deve-se investigar o melhor líquido extrator. Toledo et al. (2003) e Maciel et al. (2006) investigaram para Symphytum officinale e Lychnophora, respectivamente, as características físico-quimicas de extratos de forma semelhante às realizadas nesse trabalho.

A amostra de pó de chá verde utilizada para preparar as tinturas apresentou $25,2 \%$ de polifenóis. Esse valor, maior do que nas tinturas, indica que o processo de maceração não extrai completamente os princípios ativos da planta, conforme descreve Sharapin (2000). Deve-se destacar que o objetivo desse trabalho foi empregar a maceração, por ser um método simples, de baixo custo e muito usado na produção de tinturas e não investigar diferentes métodos de extração.

De acordo com os resultados obtidos na curva de calibração obteve-se a equação da reta: $y=25,8 x-0,034$, a partir da qual foi determinada a porcentagem de polifenóis em cada tintura. $\mathrm{O}$ coeficiente de correlação foi $R^{2}=0,990$.

A seletividade destes quatro sistemas de solventes em extrair especificamente os polifenóis do chá verde foi calculada a partir do cálculo da razão entre os teores de polifenóis e dos

TABELA 1. Características físico-químicas das tinturas de chá verde (médiasıEPM).

\begin{tabular}{c|c|c|c|c}
\hline TINTURA & $\begin{array}{c}\text { DENSIDADE } \\
\left(\mathrm{g} \cdot \mathrm{mL}^{-1}\right)\end{array}$ & $\mathrm{pH}$ & RESÍDUO SECO $(\%)$ & $\begin{array}{c}\text { POLIFENÓIS } \\
(\% \mathrm{~m} / \mathrm{v})\end{array}$ \\
\hline Tintura - EtOH $60 \%$ & $0,9049 \pm 0,002$ & $5,67 \pm 0,01$ & $0,944 \pm 0,05$ & $16,83 \pm 0,06$ \\
\hline Tintura - EtOH 70\% & $0,8755 \pm 0,003$ & $5,73 \pm 0,03$ & $0,923 \pm 0,03$ & $16,34 \pm 0,04$ \\
\hline Tintura - EtOH 80\% & $0,8511 \pm 0,003$ & $5,74 \pm 0,03$ & $0,912 \pm 0,03$ & $14,34 \pm 0,04$ \\
\hline Tintura - EtOH 94,5\% & $0,8190 \pm 0,002$ & $5,76 \pm 0,02$ & $0,904 \pm 0,01$ & $11,78 \pm 0,03$ \\
\hline
\end{tabular}

$\mathrm{EtOH}=$ etanol 
resíduos secos obtidos para cada tintura (índice de seletividade) (Ardisson et al., 2002). Pode-se observar que, para as tinturas obtidas com álcool etílico a 60 ou $70 \%$, houve a extração de maior quantidade de constituintes químicos do chá verde (Tabela 2). Essas tinturas também foram mais seletivas na extração dos polifenóis da planta. Estes dados permitem sugerir que a utilização de álcool etílico a 60 ou $70 \%$ conduz à obtenção de tinturas mais enriquecidas com os polifenóis, a partir das folhas do chá verde (C. sinensis). Como não foi aplicado teste estatístico entre as diferentes tinturas, esses resultados são apenas sugestivos e visam destacar a importância de se investigar o melhor líquido extrator. Ardisson et al. (2002) procederam de forma semelhante a esse trabalho, em estudos com barbatimão, objetivando alcançar a otimização de extratos glicólicos enriquecido em taninos. Evidentemente que para definir pontualmente a melhor condição é necessária a análise estatística dos dados.

Ardison et al. (2002) estudaram as condições de otimização da extração de taninos, compostos fenólicos presentes na casca de barbatimão (Stryphnodendron adstringens) e observaram que

TABELA 2. Índices de seletividade de tinturas de chá verde (médias).

\begin{tabular}{cc}
\hline Tintura & Índice de seletividade \\
\hline Tintura - EtOH $60 \%$ & $17,83 \pm 0,03$ \\
Tintura - EtOH $70 \%$ & $17,70 \pm 0,02$ \\
Tintura - EtOH $80 \%$ & $15,72 \pm 0,04$ \\
Tintura - EtOH $94,5 \%$ & $13,03 \pm 0,04$ \\
\hline
\end{tabular}

o extrato glicólico produzido na proporção de $70 \%$ de propilenoglicol (PGL) em água extraiu maior quantidade de princípios ativos; entretanto, o uso do solvente PGL a $80 \%$ foi mais seletivo na extração de taninos. Esses autores concluem que são necessárias avaliações das melhores condições de extração em estudos com outras plantas medicinais.

Em relação ao perfil cromatográfico em camada delgada, as tinturas não apresentaram diferenças. Foram observadas as mesmas manchas e com as mesmas intensidades nas quatro tinturas preparadas. $\mathrm{O}$ aparecimento de quatro manchas ou bandas azuis fluorescentes, com $\mathrm{Rf} \sim 0,9 ; \mathrm{Rf} \sim 0,79$; $\mathrm{Rf} \sim 0,67$ e $\mathrm{Rf} \sim 0,35$ (indicativa de polifenóis); e uma banda amarela-avermelhada com $\mathrm{Rf} \sim 0,57$ (flavonoide) foi verificado nas amostras quando observada sob comprimento de onda $365 \mathrm{~nm}$ (Figura 1A). As bandas apresentam coloração marron escuro, quando observadas em 254 nm (Figura 1B).

Deve-se ressaltar que as drogas vegetais empregadas no preparo de extratos apresentam composição complexa, possuindo os constituintes responsáveis pela ação terapêutica (por exemplo, alcaloides, glicosídeos, taninos, óleos essenciais) e, por outro lado, as substâncias desprovidas de valor terapêutico ou cuja presença ocasiona problemas farmacotécnicos de turvação, contaminação, precipitação (por exemplo, açúcares, amido, goma, substâncias protéicas, lipídeos). A dissolução seletiva consegue-se com a variação do teor alcoólico do líquido extrator (misturas hidroalcoólicas). Além disso, dentre as condições de extração, pode-se ressaltar que há numerosos fatores que influenciam na extração, tais como grau de divisão de droga, agitação, temperatura, tempo, pH, tensão superficial

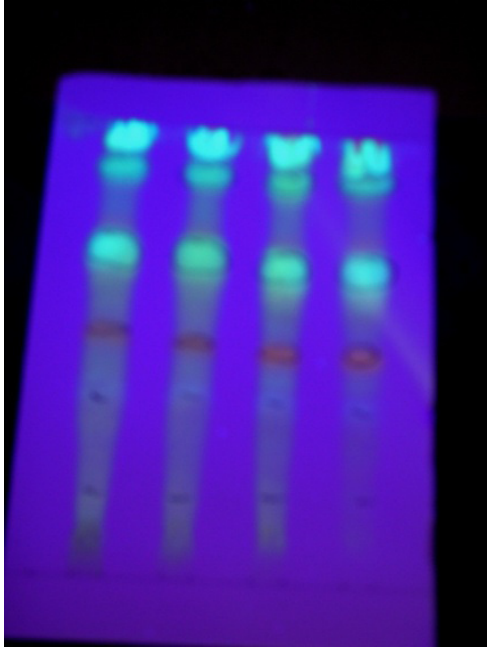

A

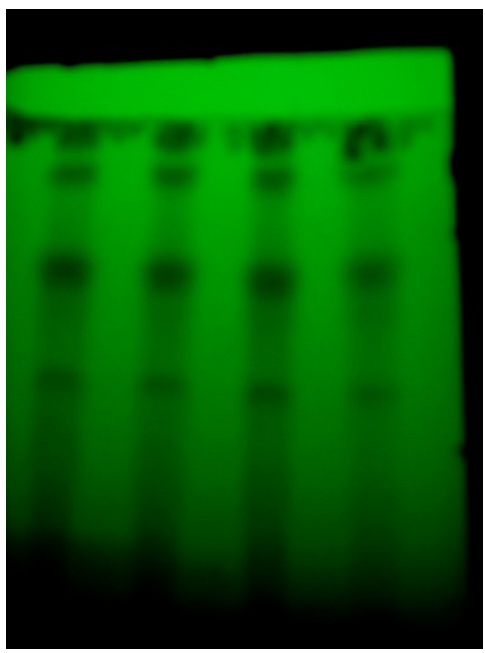

B

FIGURA 1. Perfil cromatográfico em camada delgada das tinturas de chá verde obtidas. A) revelada com NP/365 $\mathrm{nm}$. B) revelada com NP/254 nm. Fotografada com câmera digital Olympus Camedia D-435. Essa imagem não reporta à cor original das bandas. 
e natureza do líquido extrator e volume do líquido extrator (List \& Schmidt, 1989; Sharapin, 2000). Outro aspecto que deve ser considerado é que o processo de extração é uma etapa importantíssima na padronização de extratos vegetais, etapa essa requerida para a qualidade de produtos fitofarmacêuticos, uma vez que o conteúdo dos compostos ativos deve ser declarado para atender as normas regulatórias (ex.: no Brasil - ANVISA) (Chirinos et al., 2007; Cortés-Rojas et al., 2013; Zöllner \& Schwarz, 2013).

Os resultados encontrados permitem sugerir que as soluções hidroalcoólicas a $60 \%$ ou a $70 \%$ foram as mais apropriadas para a extração dos polifenóis do chá verde Camellia sinensis, nas condições experimentais utilizadas. Não se utilizou como líquido extrator mistura hidroalcoólica com concentrações alcoólicas abaixo de $60 \%$ devido a problemas de conservação e dificuldades de concentração das tinturas.

No mercado atual encontra-se disponível extrato seco padronizado de chá verde, com $20 \%$ de catequinas, não sendo revelado o solvente empregado pelo fabricante. Neste trabalho preparou-se a tintura e, para a obtenção do extrato seco, seria necessário a evaporação do solvente e então a quantificação do teor de polifenóis, que possivelmente estaria acima do valor encontrado no mercado, pois, para a tintura, encontraram-se cerca de $17 \%$ de polifenóis.

É indispensável que o fabricante de insumos farmacêuticos derivados de drogas vegetais conheça profundamente as matérias primas empregadas a fim de estabelecer, para cada uma delas, uma monografia completa que servirá como documento básico para o estabelecimento de especificações para o controle da qualidade e das instruções para as transformações (Cechinel Filho \& Yunes, 1998).

Os resultados permitem sugerir que para cada planta medicinal deve ser feito um estudo visando definir as melhores condições de elaboração de seus extratos, visto as peculiaridades de cada espécie vegetal em termos de características químicas.

\section{REFERÊNCIAS}

ABIFISA. Associação Brasileira das Empresas do Setor Fitoterápico, Suplemento alimentar e de promoção à saúde. 2007. Disponível em: <http:// www.abifisa.org.br. Acesso em: 13 jan. 2008.

ARDISSON, L. et al. Preparação e caracterização de extratos glicólicos enriquecidos em taninos a partir das cascas de Stryphonodedron adstringens (Mart) Coville (Barbatimão), Revista Brasileira de
Farmacognosia, v.12, n.1, p.27-34, 2002.

BARBOSA-FILHO, J.M. et al. Natural products inhibitors of the angiotensin converting enzyme (ACE). A review between 1980- 2000. Revista Brasileira de Farmacognosia, v.16, n.3, p.42146, 2006.

BENTHIN, B. et al. Pressurized liquid extraction of medicinal plants. Journal of Chromatography A, v.837, n.1-2, p.211-9, 1999.

CECHINEL FILHO, V.; YUNES, A.R. Estratégias para a obtenção de compostos farmacologicamente ativos a partir de plantas medicinais. Conceitos sobre modificação estrutural para otimização da atividade. Química Nova, v.21, n.1, p.99-103, 1998.

CHIRINOS, R. et al. Optimization of extraction conditions of antioxidant phenolic compounds from mashua (Tropaeolum tuberosum Ruíz \& Pavón) tubers. Separation and Purification Technology, v.55, n.2, p.217-225, 2007.

CORTÉS-ROJAS, D.F. et al. Bioactive compounds in Bidens pilosa L. populations: a key step in the standardization of phytopharmaceutical preparations. Brazilian Journal of Pharmacognosy, v. 23, n.1, p.28-35, 2013.

COSTA-MACHADO, A.R.M.; BASTOS, J.K.; FREITAS, L.A.P. Dynamic maceration of Copaifera langsdorffii leaves: a technological study using fractional factorial design. Brazilian Journal of Pharmacognosy, v.23, n.1, p.79-85, 2013.

COUZINET-MOSSION, A. et al. Interaction mechanisms between caffeine and polyphenols in infusions of Camellia sinensis leaves. Food Chemistry, v.119, n. 1, p.173-181, 2010.

DAS, A.S.; MUKHERJEE, M.; MITRA, C. Evidence for a prospective anti-osteoporosis effect of black tea (Camellia sinensis) extract in a bilaterally ovariectomized rat model. Asia Pacific Journal of Clinical Nutrition, v. 13, n.2, p. 210-216, 2004.

DUARTE, M.R.; MENARIM, D.O. Morfodiagnose da anatomia foliar e caulinar de Camellia sinensis (L.) Kuntze, Theaceae. Revista Brasileira de Farmacognosia, v.16, n.4, p.545-51, 2006.

FANG, Q. et al. Micelle-mediated extraction and preconcentration of ginsenosides from Chinese herbal medicine. Journal of Chromatography A, v.904, n.1-2, p. 47-55, 2000.

FARMACOPÉIA BRASILEIRA: 5ed. Brasilia: Anvisa, 2010. 546p.

FIORINI, R.N. et al. Short-term administration of (-)-epigallocatechin-gallate reduces hepatic steatosis and protects against warm hepatic ischemia/reperfusion injury in steatotic mice. Liver Transplant, v.11, n.3, p.298-308, 2005.

HALDER, A. et al. Black tea (Camellia sinensis) as a hemopreventive agent in oral precancerous lesions. Journal of Environmental Pathology and

Rev. Bras. PI. Med., Campinas, v.16, n.4, p.826-831, 2014. 
Toxicological Oncology, v.24, n.2, p.141-4, 2005.

KALRA, N. et al. Antioxidant potential of black tea against 7,12-dimethylbenz(a) anthracene induced oxidative stress in Swiss albino mice. Journal of Environmental Pathology and Toxicological Oncology, v.24, n.2, p.105-14, 2005.

LIANG, Y. et al. Comparison of chemical compositions of Ilex latifolia Thumb and Camellia sinensis L. Food Chemistry, v.75, n.3, p.339-43, 2001.

LIAO, Z.G. et al. Optimization of microwave-assisted extraction of active components from Yuanhu zhitong prescription.Separation and Purification Technology, v. 63, n.2, p. 424-433, 2008.

LIST, P.H.; SCHMIDT, P.C. Phytopharmaceutical Technology. Londres: Heyden \& Son Limeted, 1989. 374p.

MACIEL, R.L. et al. Características físico-químicas e químicas e estudo preliminar de estabilidade de tinturas preparadas com espécies de arnica Lychnophora em comparação com Arnica montana. Revista Brasileira de Farmacognosia, v.16, n.1, p.99-103, 2006.

NAG-CHAUDHURI, A.K. et al. Anti-inflammatory activity of Indian black tea (Sikkim variety). Pharmacological Research, v.51, n.2, p.169-75, 2005.

NORIEGA, P. et al. Avaliação por análise fatorial das condições da extração do 4-nerolidilcatecol de Pothomorphe umbellata (L). Miq. Revista Brasileira de Ciências Farmacêuticas, v.41, n.2, p.261-9, 2005.

SAITO, M.L., OLIVEIRA, F. Morfodiagnose e identificação cromatográfica em camada delgada de chá de bugre Cordia ecalyculata Vell. Revista Brasileira de Farmacognosia v.67, n.1-3, p.116, 1986.

SANTANA, I.G. et al. Determinação do perfil cromatográfico de extratos secos vegetais. Revista Eletrônica de Farmácia, v.4, n.2S, p.547, 2007.

SENGER, A. E.V.; SCHWANKE, C.H. A.; GOTTLIEB, M.G.V. Chá verde (Camellia sinensis) e suas propriedades funcionais nas doenças crônicas não transmissíveis. Scientia Medica. v. 20, n. 4, p. 292-300, 2010.

SCHMITZ, W. et al. O. O chá verde e suas ações como quimioprotetor. Semina: Ciências Biológicas e da Saúde. v. 26, n. 2, p.119-130, 2005.

SHARAPIN, N. Fundamentos de Tecnologia de Produtos Fitoterápicos. Santafé de Bogotá Colômbia : Cyted. 2000. 248p.

ONG, E.S. Extraction methods and chemical standardization of botanicals and herbal preparations. Journal of Chromatography B, v.812, n.1-2, p.23-33, 2004.

ONG, E.S.; LEN, S.M. Pressurized hot water extraction of berberine, baicalein and glycyrrhizin in medicinal plants. Analytica Chimica Acta, v.482, n.1, p.81-9, 2003.

PRADO, C.C. et al. Avaliação do teor de polifenóis da Camellia sinensis (Chá Verde). Revista Eletrônica de Farmácia, v.2, n.2 supl., p.164-7, 2005.

POMPEU, D.R.; SILVA, E.M.; ROGEZ, H. Optimisation of the solvent extraction of phenolic antioxidants from fruits of Euterpe oleracea usin response surfacemethodology. Bioresource Technology, v.100, n.23, p.6076-6082, 2009.

TOLEDO, A.C.O. et al. Análise farmacognóstica da droga e do extrato fluido das folhas de Symphytum officinale L. (Boraginaceae). Revista Brasileira de Farmacognosia, v.14, supl.2, p.1- 2, 2003.

TURCHETTI, B. et al. In vitro antimycotic activity of some plant extracts towards yeast and yeastlike strains. Phytotherapy Research, v.19, n.1, p.44-9, 2005.

USP 36- UNITED STATES PHARMACOPOEA - The National Formulary - NF 31, Second Supplement, Rockville, 2013. 3222p.

YAM, T.S. et al. Microbiological activity of whole and fractioned crude extracts of tea (Camellia sinensis), and of tea components. FEMS Microbiology Letters, v.152, n.1, p.169-74, 1997. WATERMAN, P.G.; MOLE, S. Analysis of phenolic plant metabolites. Oxford: Blackwell Scientific Publications, 1994. 238p.

ZÖLLNER, T.; SCHWARZ, M. Herbal Reference Standards: applications, definitions and regulatory requirements. Brazilian Journal of Pharmacognosy, v. 23, n.1, p. 1-21, 2013. 